\title{
EVIDÊNCIAS EMPÍRICAS SOBRE A RELAÇÃO ENTRE O PIB E OS GASTOS PÚBLICOS NOS MUNICÍPIOS PARANAENSES: UMA ABORDAGEM ESPACIAL
}

Michele Aparecida Nepomuceno Pinto ${ }^{1}$ José Luiz Parré2

Resumo: Este artigo é um estudo empírico sobre a relação existente entre gastos públicos e a formação do PIB per capita nos municípios paranaenses para o ano de 2010. Para tanto, foi utilizado um modelo econométrico espacial com o objetivo de verificar se essa relação entre gastos públicos e PIB per capita possui efeitos de transbordamento para os demais municípios do Estado. Os resultados encontrados mostram que as despesas têm impacto relevante e positivo sobre o PIB per capita dos municípios, bem como possuem externalidade espacial. Conclui-se que os governos municipais devem procurar promover o crescimento do PIB alocando seus gastos em áreas que busquem garantir uma melhor estrutura de investimento, bem como deve haver uma coordenação entre municípios vizinhos de forma que o crescimento de uma cidade promova o crescimento das cidades das redondezas, 0 que leva a um ganho para a região toda.

Palavras-chave: Desigualdades regionais. Gastos públicos. Produto Interno Bruto. Paraná.

\section{EMPIRICAL EVIDENCE ON THE RELATIONSHIP BETWEEN GDP AND PUBLIC EXPENDITURE IN PARANA MUNICIPALITIES: A SPATIAL APPROACH}

Abstract: This article is an empirical study on the relationship between public spending and the formation of per capita GDP in Paraná municipalities for the year 2010. Therefore, a spatial econometric model was used in order to check whether this relationship between public spending and GDP per capita has spillover effects to other municipalities. The results show that public expenditure has significant and positive impact on GDP per capita of municipalities and have spatial externality. Therefore, it is concluded that municipal governments should seek to promote GDP growth allocating their spending in areas that seek to ensure a better investment structure and must be coordinated between neighboring municipalities so that the growth of a city promotes the growth of surrounding cities, which means a gain for the region as a whole.

Keywords: Regional inequalities. Public expenditure. Gross Domestic Product. Paraná.

\section{EVIDENCIAS EMPÍRICAS SOBRE LA RELACIÓN ENTRE EL PIB Y LOS GASTOS PÚBLICOS EN LOS MUNICIPIOS PARANAENSES: UN ENFOQUE ESPACIAL}

Resumen: Este artículo es un estudio empírico sobre la relación existente entre gastos públicos y la formación del PIB per cápita en los municipios paranaenses para el año 2010. Para ello se utilizó un modelo econométrico espacial con el

\footnotetext{
${ }^{1}$ Universidade Estadual de Maringá, Departamento de Economia, Maringá, Brasil, mi_nepomuceno@hotmail.com, https://orcid.org/0000-0002-6446-484.

${ }^{2}$ Universidade Estadual de Maringá, Departamento de Economia, Maringá, Brasil, jplparre@gmail.com, 
objetivo de verificar si esa relación entre gastos públicos y el PIB per cápita tiene efectos de desbordamiento para los demás municipios del Estado. Los resultados encontrados muestran que los gastos tienen un impacto relevante y positivo sobre el PIB per cápita de los municipios, así como tienen externalidad espacial. Se concluye que los gobiernos municipales deben procurar promover el crecimiento del PIB asignando sus gastos en áreas que busquen garantizar una mejor estructura de inversión, así como debe haber una coordinación entre municipios vecinos de forma que el crecimiento de una ciudad promueve el crecimiento de las ciudades de las cercanías, lo que lleva a una ganancia para toda la región.

Palabras clave: Desigualdades regionales. Gastos públicos. Producto Interno Bruto. Paraná.

\section{Introdução}

O crescimento econômico, mensurado através da proxy Produto Interno Bruto (PIB), é uma medida utilizada quando se objetiva analisar o grau de desenvolvimento de uma região. A atuação do governo através de seus gastos é um relevante determinante desse crescimento, fato evidenciado no trabalho teórico de Barro (1990) e em vários outros estudos empíricos [ARRAES e TELES (2001); ROCHA e GIUBERTI (2005); MARQUES JÚNIOR et al. (2006) e RODRIGUES e TEIXEIRA (2010)].

A literatura econômica considera a infraestrutura local como determinante do crescimento econômico municipal. Oliveira (2006) afirma que gastos produtivos ajudam a equilibrar a distribuição espacial das atividades, afetando positivamente o crescimento econômico dos municípios. É incontestável a importância do governo local para o crescimento dos municípios, sendo assim, a política fiscal local deve ser bem elaborada, de modo a gerar o máximo de benefícios econômicos e sociais possíveis ao próprio município e ao seu entorno.

Costa et al. (2007 apud Forlin e Rodrigues, 2012) afirmam que uma política fiscal realizada pela prefeitura de forma eficiente apresenta, na maioria das vezes, resultados positivos. Esta política deve ser eficiente no sentido de gerar crescimento para o município e possibilitar um padrão mais elevado na produtividade de diversos setores econômicos. Desta forma, os investimentos que aumentam a qualificação e a qualidade de vida dos indivíduos, merecem destaque na pauta de discussões sobre crescimento econômico (FORLIN e RODRIGUES, 2012). Sendo assim, fica claro que o investimento público é relevante para o fornecimento de infraestrutura e de bens públicos geradores de externalidades positivas, favorecendo as empresas e o próprio crescimento econômico municipal. 
Com base na importância do dispêndio governamental para o crescimento econômico municipal, o presente estudo tem por objetivo investigar a relação existente entre o crescimento econômico, considerando o Produto Interno Bruto (PIB) per capita municipal paranaense, e as variáveis que compõem os gastos públicos (gasto total, gastos com pessoal, gastos administrativos, gastos com saúde e com educação) dos 399 municípios paranaenses.

A pesquisa justifica-se pela relevância que a política fiscal possui para 0 desenvolvimento e no processo de estabilização econômica municipal. No contexto atual, a política macroeconômica tem como elemento fundamental o ajuste fiscal, no sentido de reforçar o aumento da produtividade dos gastos públicos, bem como a busca por uma alocação cada vez mais eficiente e capaz de alavancar o setor produtivo (BOGONI, HEIN e BEUREN, 2011).

Desta forma este trabalho está organizado em seis seções, sendo a primeira esta introdução. A segunda apresenta algumas relações entre crescimento econômico e gastos públicos no Brasil, bem como o papel da econometria espacial nos modelos de crescimento econômico. A terceira seção apresenta a metodologia do trabalho, com ênfase nos modelos de econometria espacial e na forma como são construídos. Na quinta seção são apresentados os principais resultados do trabalho e por fim são feitas algumas considerações finais.

\section{A relação entre gastos públicos e crescimento econômico}

A política fiscal é um dos mecanismos mais eficientes de que o governo dispõe para elevar ou diminuir a renda da economia, uma vez que, ao fazer parte da demanda agregada, qualquer alteração dos gastos do governo provocará alterações no nível de renda da economia, dado o efeito multiplicador que esta variação apresenta, uma vez que a produção também deverá variar para atender à modificação na demanda.

A participação do gasto público na composição da demanda agregada deve ser vista como uma externalidade positiva na economia, uma vez que o tamanho do governo tem efeito positivo no desempenho e no crescimento econômico para o restante da economia. Assim, dado o efeito multiplicador, um governo que seja atuante e que crie demanda para seus gastos tende a elevar o crescimento econômico, inclusive por meio do aumento da produtividade do setor privado. 
Segundo Bogoni, Hein e Beuren (2011), Adolf Wagner foi um dos primeiros economistas a postular uma relação entre gastos públicos e crescimento econômico através da criação da chamada Lei dos Dispêndios Públicos Crescentes, onde ele defendia que o crescimento da renda per capita (ou o desenvolvimento econômico em termos gerais) exigiria a participação cada vez maior do governo na oferta de bens públicos. Essa participação deveria ser crescente a ponto de desenvolver a economia eficientemente, aumentando a relação entre gastos públicos e o PIB.

Ao se analisar os estudos relacionados ao desenvolvimento regional desigual fica claro que, para alguns autores, a tendência ao crescimento distinto pode ser amenizada com a aplicação de ações do Estado. Myrdal (1968 apud Barros e Ferreira, 2012), ao defender a existência de um ciclo vicioso de atraso como consequência do desenvolvimento regional, afirmava que o Estado seria o único agente capaz de minimizar os efeitos dessa causação circular acumulativa, reduzindo as disparidades existentes entre as regiões periféricas e as regiões consideradas polos de desenvolvimento através de políticas igualitárias e protetoras do mercado interno.

Já para Furtado (1974), uma vez que um processo de disparidades tenha iniciado, a sua reversão espontânea é quase que impossível e, desse modo, tornase essencial o papel do Estado, haja vista que o processo de acumulação tende a alargar o distanciamento entre os centros de desenvolvimento e as economias periféricas.

Como se sabe, o Brasil possui grandes disparidades regionais, onde algumas regiões são extremamente mais desenvolvidas que outras, atraindo assim, mais investimentos produtivos em detrimento das demais, isso leva a um aumento dessas disparidades, cabendo, portanto, ao gestor público o papel de promover o desenvolvimento às regiões periféricas. Guimarães Neto (1997) aponta a necessidade de que essa participação do Estado aconteça através de políticas específicas de desenvolvimento para cada região, de modo que o objetivo final seja garantir que essas regiões tornem-se eficientes e competitivas diante de um cenário econômico de globalização.

O debate se dá, portanto, em quais gastos seriam os mais eficientes no sentido de promover o crescimento de determinada região e uma maior igualdade entre elas. Para Diniz e Crocco (2006), as políticas de desenvolvimento regional no Brasil devem buscar reforçar a capacidade de investimento, criar sistemas locais de pesquisa e inovação, melhorar o sistema educacional, melhorar a infraestrutura de 
transportes e telecomunicações e reorientar o sistema de subsídios e incentivos. Já para Lima e Lima (2011) há necessidade de uma política regional em uma perspectiva mais ampla, que não leve somente em consideração a questão do crescimento em si, mas também as que envolvam outras áreas como 0 desenvolvimento tecnológico e o social. Dessa forma, deve-se buscar impulsionar a dinâmica local em um cenário global a fim de que se consiga produzir o crescimento em longo prazo (BARROS E FERREIRA, 2012).

Diante do exposto fica evidente que não há uma única maneira de se promover o crescimento econômico de uma região através dos gastos públicos. Porém, a literatura aponta alguns gastos que tendem a ser mais eficientes na formação do PIB e na promoção do crescimento econômico. Barro (1990) propõe a divisão entre gastos públicos improdutivos e gastos públicos produtivos. Os gastos improdutivos são aqueles que não afetam o crescimento econômico de longo prazo; por sua vez, os gastos produtivos afetam positivamente o crescimento econômico de longo prazo. Esses gastos são capazes de influenciar diretamente na produtividade do setor privado, atraindo, portanto, investimentos deste setor para essas regiões menos desenvolvidas. Segundo o autor, esses gastos seriam os que preservam os direitos de propriedade e os serviços em infraestrutura, educação e saúde. Tais gastos afetam diretamente a função de produção e podem impulsionar a economia da região.

Oliveira (2006) afirma que gastos produtivos ajudam a equilibrar a distribuição espacial das atividades, afetando positivamente o crescimento econômico dos municípios. Castro (2006, apud Barros e Ferreira, 2012), aponta que, para determinar o impacto da política fiscal no crescimento econômico, é preciso conhecer o tipo de impostos e de despesas públicas, o nível total das despesas públicas e o tipo de financiamento. O autor acredita que de forma geral os gastos em investimento, educação, saúde e habitação, que afetariam a acumulação de capital humano e, consequentemente, a produtividade marginal do capital e do trabalho, são produtivos.

No concernente a produção empírica voltada a caracterizar os gastos públicos mais significativos na formação do produto das regiões, destacam-se os trabalhos propostos por Arraes e Teles (2001); Rocha e Giuberti (2005); Marques Júnior et al. (2006) e Rodrigues e Teixeira (2010).

Arraes e Teles (2001) buscaram verificar os efeitos das políticas fiscais sobre o crescimento econômico. Para analisar o período de 1981 a 1995, os autores 
utilizaram um modelo em que se tem o Produto Interno Bruto (PIB) como variável dependente, e gastos públicos, capital humano e capital físico como variáveis explicativas. Eles concluíram que os gastos públicos que apresentaram efeitos mais significantes na determinação do produto foram os com educação, cultura e infraestrutura.

O trabalho proposto por Rocha e Giuberti (2005) buscou avaliar quais os componentes do gasto público que contribuíram para o crescimento econômico dos estados brasileiros entre o período de 1986 a 2002, para tanto utilizaram dados em painel e consideraram as despesas públicas como variáveis explicativas para a taxa de crescimento do PIB per capita. As autoras mostraram que a relação entre o crescimento econômico com os gastos com defesa, educação, transporte e comunicação é positiva.

Bogoni, Hein e Beuren (2011) objetivando investigar a relação existente entre o crescimento econômico e as variáveis que compõem os gastos públicos das maiores cidades da Região Sul do Brasil, avaliaram como os gastos em saúde, saneamento, educação, cultura, investimentos públicos, habitação, assistência e previdência afetam o PIB dos municípios para o período de 2001 a 2004. Os resultados encontrados apontaram para uma relação positiva, de modo que os gastos dos governos locais têm efeito positivo na produtividade e na qualidade de vida dos trabalhadores e, por consequência, no crescimento econômico.

Os estudos considerados até então convergem para a ideia de que as políticas públicas são importantes no processo de crescimento e desenvolvimento da economia de um município, região ou país. Sendo assim, tais medidas devem ser priorizadas, principalmente em regiões de extrema desigualdade e atraso econômico.

A partir dessas evidências empíricas, o presente trabalho tem como objetivo analisar a relação entre os gastos públicos e o crescimento econômico dos municípios paranaenses no ano de 2010, bem como verificar se há evidências de um espraiamento desse crescimento entre as cidades do estado. Desse moo se buscará compreender a natureza dessas relações nos municípios paranaenses, a fim de que se possa contribuir na definição de uma melhor forma de alocar as despesas dos governos locais na busca da promoção e sustentação do crescimento econômico municipal. 


\section{O papel da econometria espacial nos modelos de crescimento econômico}

Segundo Forlin e Rodrigues (2012), o economista Von Thünen (1826), foi um dos primeiros autores a discutir a localização no âmbito da Economia Regional. O autor criou um modelo da cidade isolada onde discute as decisões de localização baseando-se no preço da terra e custo de transporte, mostrando que nenhuma cidade pode viver isolada das outras, ou seja, há uma certa dependência espacial.

A partir desse primeiro estudo muitos outros surgiram, levando ao surgimento da Nova Geografia Econômica, sendo seus principais expoentes Paul Krugman, Masahisa Fujita e Anthony Venables. A Nova Geografia Econômica (NGE) diferencia-se das demais teorias, por considerar dois aspectos: o espaço, que influencia na localização das atividades; e as distâncias, que trazem efeitos nos custos de transporte de bens e serviços, tornando, assim, uma região mais atrativa que outra. Sob a visão da NGE, existem externalidades positivas, ou forças centrípetas, que levam à aglomeração das atividades, e externalidades negativas, ou forças centrífugas, que levam a dispersão das atividades entre as regiões (FORLIN e RODRIGUES, 2012).

De acordo com a perspectiva da NGE, a aglomeração das atividades eleva a produtividade, o que influencia as taxas de crescimento de renda e emprego. Com isso, a NGE explica o desenvolvimento e o subdesenvolvimento de uma região, de uma forma que deixa os formuladores de políticas econômicas apenas com um meio de lutar contra essas forças: a política fiscal. O governo, por meio de incentivos fiscais e investimentos, pode atrair atividades econômicas para a região e, assim, impactar seu crescimento econômico (OLIVEIRA et al., 2009 apud FORLIN e RODRIGUES, 2012).

Ou seja, o gasto público tem papel primordial no desenvolvimento de uma região, pois é ele quem vai estimular a economia, gerando renda para a sociedade e é, também, quem vai atrair os investimentos privados, uma vez que uma cidade precisa ter atrativos, tais como, mão de obra qualificada, perspectiva de demanda, boa qualidade de vida, etc, ou nenhum empresário terá incentivos a investir nessa região. Assim, as despesas municipais devem ocorrer de forma consciente e buscando o desenvolvimento das áreas que mais geram retornos em termos de crescimento no município. Ao fazer isso, mesmo que inconscientemente, o gestor público está criando fatores importantes para o crescimento e desenvolvimento das 
regiões próximas a seu município, promovendo, dessa maneira, o desenvolvimento da região como um todo.

\section{Metodologia}

A metodologia deste trabalho está dividida em duas partes: na primeira, será exposta a explicação das variáveis utilizadas no artigo, enquanto na segunda estarão expostos os instrumentais de análise de dados espaciais e os modelos econométricos espaciais a serem testados.

\section{Descrição dos Dados}

Os dados utilizados no trabalho referem-se à malha de municípios georreferenciada do Paraná (arquivo shapefile), ou seja, 399 municípios. A análise econométrica espacial foi feita sob a forma de cross-section para o ano de 2010 devido à limitação de dados mais recentes disponíveis para todos os municípios. Todos os dados foram extraídos da base de dados online do Instituto Paranaense de Desenvolvimento Econômico e Social - IPARDES e todas as variáveis - exceto, naturalmente, o PIB per capita e distância à capital - foram intensificadas pela estimativa oficial da população de cada unidade municipal. Foi realizada a transformação de todas as variáveis em logaritmo natural (In) para melhor análise dos dados. Para a manipulação dos dados juntamente com os mapas foi utilizado o software Geoda.

Seguindo os modelos propostos por Barros e Ferreira (2012) e Bogoni, Hein e Beuren (2011), a variável dependente é o Produto Interno Bruto per capita municipal. As variáveis de despesa explicativas são despesa total, despesa com pessoal, despesa administrativa, despesa com saúde e despesa com educação. Além dessas, foram utilizadas a densidade demográfica, a distância à capital e a utilização de energia elétrica como variáveis de controle. A Tabela 1 apresenta o resumo das variáveis utilizadas no modelo e a descrição destas.

A Tabela 1 apresenta a estatística descritiva dos dados utilizados no trabalho. Vê-se que o PIB per capita dos municípios paranaenses é, em média de $R \$$ 14.628,77 (ainda não linearizado), sendo que o menor valor é o da cidade de Piraquara, com um PIB per capita de $\mathrm{R} \$ 5.869,00$; esse valor é considerado baixo, uma vez que esta cidade detinha, em 2010, uma população de 93.207 habitantes e 
o município que apresentou o maior PIB per capita no ano analisado foi o de Araucária, também na região metropolitana de Curitiba, com uma população de 119.123 habitantes, seu PIB per capita foi de $R \$ 103.778,00$. Quanto às despesas, em geral essas apresentaram desvio padrão baixos, logo se pode afirmar que há certa normalidade nos gastos dos municípios de acordo com sua população. A única despesa que difere dessa média é a despesa total per capita, que apresentou um desvio padrão de 610,94.

Quadro 1: Descrição das variáveis utilizadas

\begin{tabular}{|c|c|}
\hline Variável dependente & Descrição \\
\hline $\begin{array}{l}\text { Produto Interno Bruto per capita } \\
\text { municipal (PIBpc) }\end{array}$ & $\begin{array}{l}\text { Corresponde ao valor do PIB global dividido pelo número } \\
\text { absoluto de habitantes do município. }\end{array}$ \\
\hline Variáveis explicativas & Descrição \\
\hline Despesa Total (DespTot) & $\begin{array}{l}\text { Total da despesa efetivamente realizada pelo município } \\
\text { durante o exercício fiscal. Engloba as despesas correntes e de } \\
\text { capital. }\end{array}$ \\
\hline Despesa com Pessoal (DespPes) & $\begin{array}{l}\text { Despesas de natureza remuneratória decorrentes do efetivo } \\
\text { exercício de cargo, emprego ou função de confiança no setor } \\
\text { público, do pagamento de proventos de aposentadorias e } \\
\text { reformas e pensões. }\end{array}$ \\
\hline Despesa Administrativa (DespAdm) & $\begin{array}{l}\text { Congrega as ações de captação, aplicação, orientação e } \\
\text { controle dos recursos financeiros. }\end{array}$ \\
\hline Despesa com Saúde (DespSaúde) & $\begin{array}{l}\text { Refere-se à despesa municipal total realizada com ações e } \\
\text { serviços públicos de saúde. }\end{array}$ \\
\hline Despesa com Educação (DespEduc) & Despesas decorrentes das ações voltadas para a educação. \\
\hline Densidade demográfica (DD) & $\begin{array}{l}\text { E o indicador que mostra como a população se distribui pelo } \\
\text { território, sendo determinada pela razão entre a população e a } \\
\left.\text { área de uma determinada região (hab./ } \mathrm{km}^{2}\right) \text {. }\end{array}$ \\
\hline Distância da capital (DIST) & $\begin{array}{l}\text { É a distância medida a partir do marco zero da Capital (Praça } \\
\text { Tiradentes) até o acesso à cidade em questão. }\end{array}$ \\
\hline Energia Elétrica (Energia) & $\begin{array}{l}\text { É a energia elétrica que pode ser convertida em outra forma } \\
\text { de energia. O consumo de energia é expresso em megawatts- } \\
\text { hora (mwh). }\end{array}$ \\
\hline
\end{tabular}

Fonte: Elaboração própria a partir dos dados do IPARDES.

A densidade demográfica entre os municípios também se mostra bem diversa, uma vez que o município de Alto Paraíso detém 3,07 hab/ $\mathrm{km}^{2}$, enquanto que Curitiba possui uma densidade demográfica de 4.022,79 hab/km². O município de Guaíra é o que apresenta a maior distância à capital Curitiba, enquanto que o município de Pitangueiras apresenta o maior gasto com energia elétrica per capita entre todas as cidades paranaenses.

Tabela 1: Estatística descritiva dos dados

\begin{tabular}{c|c|c|c|c}
\hline Variáveis & Média & Mínimo & Máximo & Desvio-padrão \\
\hline PIBpc $(\mathrm{R} \$)$ & $14.628,77$ & $5.869,00$ & $103.778,00$ & 8420,07 \\
DespTot $(\mathrm{R} \$)$ & $1.764,85$ & 615,51 & $4.972,95$ & 610,94 \\
DespCor $(\mathrm{R} \$)$ & $1.502,57$ & 599,54 & $4.784,97$ & 527,95
\end{tabular}




\begin{tabular}{ccccc} 
DespPes $(\mathrm{R} \$)$ & 771,98 & 342,22 & $2.222,22$ & 266,29 \\
DespAdm (R\$) & 286,44 & 37,07 & $1.105,31$ & 152,51 \\
DespSaude (R\$) & 392,63 & 15,88 & $1.051,10$ & 136,79 \\
DespEduc (R\$) & 422,05 & 179,93 & $1.056,00$ & 138,91 \\
DD (hab/km²) & 62,09 & 3,07 & $4.022,79$ & 239,97 \\
Distância $(\mathrm{km})$ & 404,60 & 0,00 & 679,86 & 158,35 \\
Energiapc $(\mathrm{mwh})$ & 0,02 & 0,0004 & 0,31 & 0,04 \\
\hline
\end{tabular}

Fonte: Elaboração própria a partir dos dados do IPARDES.

\section{Econometria espacial}

Anselin (1999, p. 1) define econometria espacial da seguinte forma: "spatial econometrics is a subfield of econometrics that deals with the treatment of spatial interaction (spatial autocorrelation) and spatial structure (spatial heterogeneity) in regression models". Considerando que as despesas públicas podem ser influenciadas por fenômenos espaciais, esse artigo utiliza como metodologia o instrumental de econometria espacial, uma vez que os modelos tradicionais de regressão linear não levam em consideração as consequências de autocorrelação e heterogeneidade espaciais.

O estudo da econometria espacial cada vez mais vem conquistando espaço na literatura econômica. Segundo Figueiredo (2002), este fato tem ocorrido por causa da constatação de que na maioria dos casos de dados de corte seccional, existe autocorrelação espacial e, também, porque existem efeitos de interdependência nas diferentes regiões, principalmente, quanto mais próxima uma região for da outra.

A dependência espacial é dada pela interação dos agentes no espaço, ou seja, o valor de uma variável de interesse numa certa região i depende do valor dessa variável nas regiões vizinhas j. A inserção da localização no estudo é importante, pois quando este não é inserido os resultados proporcionados pela econometria convencional podem se tornar inválidos. A inserção de técnicas espaciais incorpora na modelagem o padrão da interação socioeconômica entre os agentes do sistema, bem como as características da estrutura desse sistema no espaço (ALMEIDA, 2012; SILVA et al., 2013). Desse modo, a econometria espacial é utilizada quando uma variável de uma determinada localidade influencia a mesma (ou outra) característica em uma localidade geograficamente próxima. 


\section{Matriz de dados espaciais}

O primeiro passo para se criar uma regressão espacial é representar os dados espaciais na forma matricial, em que os vizinhos de cada localidade são especificados por meio da matriz de pesos especiais "Wij". Dessa forma, para cada ponto do espaço, é definido um conjunto de vizinhança que interage com ele. Os dados de vizinhança são representados na forma de uma matriz simétrica, em que aij (elemento que representa a relação de vizinhança entre o espaço $i$ e o espaço $j$ ) assume o valor de $1\left(W_{i j}=1\right)$ se os locais são vizinhos e o valor $0\left(W_{i j}=0\right)$, caso não sejam (SILVA et al., 2013).

Um dos principais métodos de ordenar as informações ao longo do espaço é a utilização do critério de contiguidade (vizinhança), que reflete a posição de uma unidade em relação às demais unidades no espaço. Quanto à dependência espacial, pressupões-se que regiões vizinhas apresentam um grau maior de dependência do que as demais.

Os dois critérios de contiguidade mais utilizados são a "Rainha" e a "Torre" em alusão aos movimentos do jogo de xadrez. Por exemplo, com o critério Rainha uma determinada região tem como vizinhos todas as demais regiões que possuem fronteiras ou vértices comuns, enquanto que o critério Torre considera como vizinhos somente os locais com fronteira em comum. Um outro critério de contiguidade que pode ser utilizado é o dos k-vizinhos mais próximos, em que a distância entre os locais é mais importante que a existência da fronteira geográfica em si.

Dados os três critérios, é necessário encontrar a matriz de pesos espaciais que melhor representa a verdadeira correlação espacial dos dados estudados. A forma mais apropriada é utilizar a matriz que apresenta o maior valor de autocorrelação espacial entre os dados.

\section{Análise Exploratória de Dados Espaciais (AEDE)}

Após ser criada a matriz de pesos espaciais, deve-se verificar se os dados apresentam dependência espacial, bem como heterogeneidade espacial. Para responder a essa pergunta usa-se a análise exploratória de dados espaciais (AEDE), cuja importância está na descrição da distribuição espacial, dos padrões de associação espacial (clusters) e identificação dos outliers. Com esse método, 
consegue-se extrair medidas de autocorrelação espacial global e local, além de investigar a influência dos efeitos espaciais (SILVA et al., 2013).

O primeiro passo no estudo da AEDE é verificar a presença de aleatoriedade dos dados espaciais. Se os dados são aleatórios, o valor de uma variável não depende dos valores dessa variável nos seus vizinhos, logo, o uso da econometria espacial não se faz necessário, porém, se o valor depender dos valores vizinhos, conclui-se que o uso de uma regressão espacial é o método mais adequado.

Para verificar se os dados espaciais são aleatórios, faz-se duas análises: a) autocorrelação espacial global e b) autocorrelação espacial local. Segundo Almeida (2012), na literatura existe um conjunto de estatísticas que investigam a presença da autocorrelação espacial, isto é, se existe a coincidência da similaridade de valores de uma variável com a similaridade da localização dessa variável.

Uma das estatísticas mais utilizada para o cálculo da autocorrelação espacial é a estatística I de Moran, onde a hipótese nula se refere à aleatoriedade espacial. Sendo $n$ o número de unidades espaciais, $Z$ o vetor de $n$ observações e $W$ a matriz de pesos espaciais utilizada, So representa o somatório dos elementos da matriz de pesos espaciais $W$.

$$
I=\left(\frac{n}{\text { So }}\right)\left(\frac{z_{t^{\prime} W z_{t}}}{z_{t^{\prime \prime}}}\right)
$$

O I de Moran varia entre -1 e 1 e fornece uma medida de associação linear entre os vetores $\left(z_{-} t\right)$ e a média ponderada dos valores da vizinhança, ou defasagens espaciais $\left(W z_{-} t\right)$. Os valores de I maiores (ou menores) do que o valor esperado $E(I)=-1 /(n-1)$ significam que há autocorrelação positiva (ou negativa). De acordo com Almeida (2012), autocorreção espacial positiva indica que a característica estudada apresenta similaridade entre seus valores, enquanto que a autocorrelação espacial negativa indica dissimilaridade entre os valores.

Visto que tanto a ausência quanto a forte presença de autocorrelação global podem ocultar associações espaciais locais, como clusters ou outliers espaciais, Anselin (1995) propôs um novo indicador capaz de capturar padrões locais de associação linear, que chamou de I de Moran local. Dessa forma, Almeida (2012) define que "o I de Moran local provê uma indicação do grau de agrupamento dos valores similares em torno de uma determinada observação, identificando clusters espaciais, estatisticamente significantes". Sua fórmula é dada por: 


$$
I=\frac{\left(y_{i}-\bar{y}\right) \sum_{j}^{n} w_{i j}\left(y_{j}-\bar{y}\right)}{\sum_{i}^{n}\left(y_{i}-\bar{y}\right)^{2} / n}
$$

Se o I de Moran Local for maior que $\mathrm{E}(\mathrm{I})$ há indicação de clusters com valores similares ao redor de $i$; já um I de Moran menor que $\mathrm{E}(\mathrm{I})$ indica clusters de valores diferentes ao redor de $i$; enquanto que I de Moran Local igual a $\mathrm{E}(\mathrm{I})$, indica ausência de clusters.

Segundo Silva et al. (2013), o diagrama de dispersão de Moran é uma forma adicional de verificar a dependência espacial. Através da representação do coeficiente da regressão, com valores normalizados sobre a média dos vizinhos, é possível visualizar a correlação linear entre $z$ (variável normalizada) e $W z$ (média dos vizinhos).

Definem-se quatro tipos desses agrupamentos de associação linear espacial, conforme verifica-se na Figura 1: o padrão de correlação Alto-Alto (AA), que é um tipo de aglomeração em que a variável de interesse apresenta valor alto e encontrase cercada por regiões apresentando valores também altos; o padrão de correlação Baixo-Baixo (BB) apresenta regiões com valores baixos rodeadas por outras também de valores baixos; o padrão Alto-Baixo $(A B)$ apresenta um valor alto da sua variável de interesse e é rodeada por regiões que apresentam valores baixos e o padrão Baixo-Alto (BA) apresenta uma unidade espacial com baixo valor da variável de interesse circundada por regiões com valores altos.

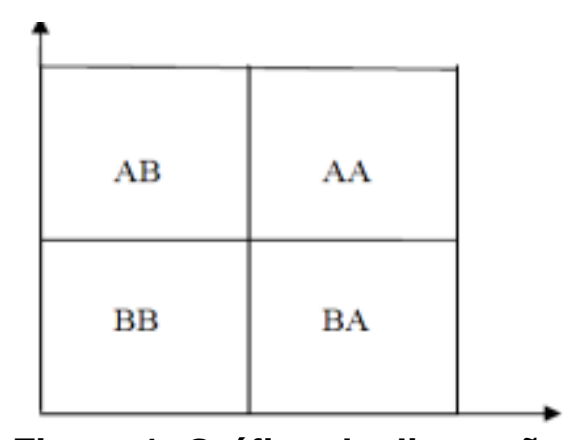

Figura 1: Gráfico de dispersão

Fonte: Elaboração própria.

Deve-se ressaltar que os locais em que estão nos quadrantes 1 e 3 denotam pontos com associação espacial positiva, ou seja, o local e a média da vizinhança apresentam valores semelhantes. As regiões com essas características formam clusters com valores similares. Por sua vez, os quadrantes 2 e 4 , apresentam autocorrelação espacial negativa, formando outliers, caracterizado pelas 
observações que não seguem o processo de dependência espacial predominante da dependência espacial dos demais dados (SILVA et al., 2013; COLUSSO, 2012).

\section{Modelos econométricos espaciais}

Com a confirmação da existência de dependência espacial entre as variáveis, a partir da Análise Exploratória dos Dados Espaciais (AEDE), o próximo passo é estimar o modelo econométrico espacial, que difere do método dos Mínimos Quadrados Ordinários (MQO) por incluir defasagens na variável dependente, defasagens na variável independente e/ou defasagens no termo de erro (CASSUSSE et al., 2007; SILVA et al., 2013).

Devido a essas defasagens, a autocorrelação espacial implica em prejuízos na estimação do modelo pelo método de Mínimos Quadrados Ordinários (MQO). Se a autocorrelação ocorre na variável dependente, as estimativas de MQO são viesadas e inconsistentes. Por sua vez, quando a correlação está presente no termo do erro, não há viés, nem inconsistência, porém, o estimador de MQO deixa de ser o mais eficiente (SILVA et al., 2013).

Para detectar a autocorrelação espacial, o primeiro teste a ser feito é a estatística I de Moran. Se confirmada a presença de autocorrelação espacial devese verificar se essa correlação ocorre na variável dependente ou no termo de erro, para isso, utiliza-se dos testes tipo Multiplicador de Lagrange (ML). O Teste ML $\rho$ analisa a defasagem espacial com a hipótese nula de $\mathrm{H} 0: \rho=0$, ou seja, de que não há defasagem espacial. Enquanto que o Teste $M L \lambda$ investiga a autocorrelação espacial no erro e tem como hipótese nula $\mathrm{H} 0: \lambda=0$, indicando que não há autocorrelação espacial.

Sendo assim, o procedimento para indicar o modelo econométrico mais apropriado é: a) estimar o modelo pelo método de MQO; b) testar a presença de autocorrelação através das estatística $M L \rho$ e $M L \lambda$; c) caso os dois testes não sejam significantes, o modelo não apresenta autocorrelação espacial e, dessa forma, o modelo "tradicional" é o mais apropriado; d) caso os dois testes sejam significantes, calcula-se as versões robustas desses testes, $M L^{*} \rho$ e $M L^{*} \lambda$ e estima-se o modelo mais significante; e) caso apenas um dos testes seja significante este é, portanto, o modelo mais adequado. 
Abaixo são apresentados os principais modelos econométricos espaciais: a) defasagem espacial, b) o modelo de erro espacial e c) cruzado espacial ou Durbin Espacial.

i. Modelo por Defasagem Espacial (MDE): este modelo é representado da seguinte forma:

$$
y=\rho W y+X \beta+\varepsilon
$$

Onde $y$ é o vetor $\mathrm{n} \times 1$ de variáveis dependentes; $\rho$ é o coeficiente autorregressivo espacial (um escalar); Wy o vetor $\mathrm{n} \times 1$ de defasagens espaciais para as variáveis dependentes; $X$ é a matriz $\mathrm{n} \times \mathrm{k}$ de variáveis explicativas; $\beta$ é o vetor $\mathrm{k} \times 1$ de coeficientes de regressão e $\varepsilon$ o vetor $\mathrm{n} \times 1$ de erros aleatórios (ALMEIDA, 2012).

Esse modelo não pode ser estimado por MQO devido à endogeneidade do regressor $W y$. Por isso, é estimado pelo estimador de máxima verossimilhança. Em relação ao $\mathrm{MQO}$, esse modelo possui um termo a mais para capturar o efeito das externalidades espaciais.

ii. Modelo de Erro Autoregressivo Espacial (MEE): este modelo é apropriado quando as variáveis não incluídas no modelo e presentes no componente do erro são autocorrelacionados espacialmente $O$ significado intuitivo desse modelo é que o padrão espacial manifestado no termo de erro é dado por efeitos não modelados por conta da falta de adequada medida, que, por sua vez, estão espacialmente autocorrelacionados (ALMEIDA, 2012). É representado por:

$$
y=\beta_{1}+\beta_{2} X+\mu
$$

Em que $\mu=\lambda W \mu+\varepsilon$. Sendo o coeficiente $\lambda$ o parâmetro do erro autorregressivo espacial que acompanha a defasagem $W \mu$. Assim como o modelo anterior, o modelo de erro espacial é estimado via estimador da máxima verossimilhança.

iii. Modelo de Durbin Espacial: O modelo de Durbin espacial, derivado do modelo de erro autorregressivo espacial de primeira ordem, incorpora a ideia de transbordamento a partir da defasagem das variáveis independentes (WX) e também pela inclusão de uma variável endógena defasada espacialmente $(W y)$. Expressa-se este modelo conforme a especificação a seguir:

$$
y=\lambda W y+X \beta-\lambda W X \beta+\varepsilon
$$




\section{Modelo proposto}

O modelo a ser estimado pode ser formalmente, representado por:

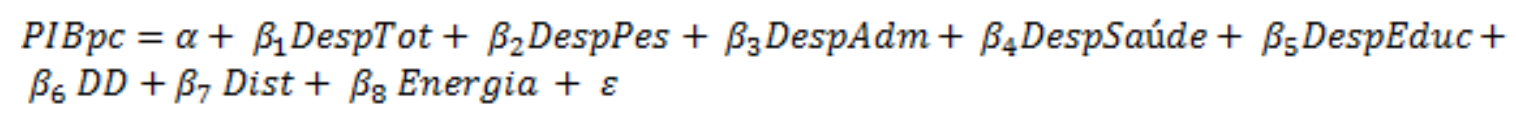

As variáveis do modelo já foram apresentadas anteriormente. É importante destacar que se espera que o PIB per capita sofra um efeito positivo das variáveis de despesa, bem como da energia e um efeito negativo da densidade demográfica e da distância à capital. A equação (6) será estimada tanto por MQO quanto pelas técnicas de econometria espacial de modo a verificar se os efeitos espaciais são significativos para estudos sobre a relação entre despesas públicas e PIB per capita.

\section{Resultados e discussões}

Esta seção apresenta os principais resultados encontrados no trabalho, seguindo a proposta metodológica onde se analisa a distribuição espacial do PIB per capita entre os municípios e verifica-se se a utilização da econometria espacial é conveniente ou não para o estudo proposto e, caso sim, qual o modelo econométrico espacial é o mais apropriado. Por fim, será estimado o modelo.

\section{Resultados da Análise Exploratória dos Dados Espaciais (AEDE)}

A Figura 2 apresenta a distribuição geográfica do PIB per capita no Estado do Paraná no ano de 2010. Vê-se que ocorrem certas aglomerações espaciais dessa variável, pois enquanto que na região Central do Estado há uma tendência de valores baixos do PIB per capita, na região metropolitana de Curitiba, na região Norte, que inclui as cidades de Maringá e Londrina e nas regiões Oeste e Sudoeste do Paraná, que inclui as cidades de Foz do Iguaçu e Pato Branco há uma tendência de altos valores do PIB per capita.

Essas aglomerações espaciais podem ser um indicativo de que ocorre uma associação espacial do PIB per capita nos municípios paranaenses, no sentido de 
que há cidades com altos valores de PIB per capita circundadas por cidades que também apresentam valores altos para essa variável, bem como há cidades com PIB per capita baixo rodeadas por outras com PIB per capita também baixo.

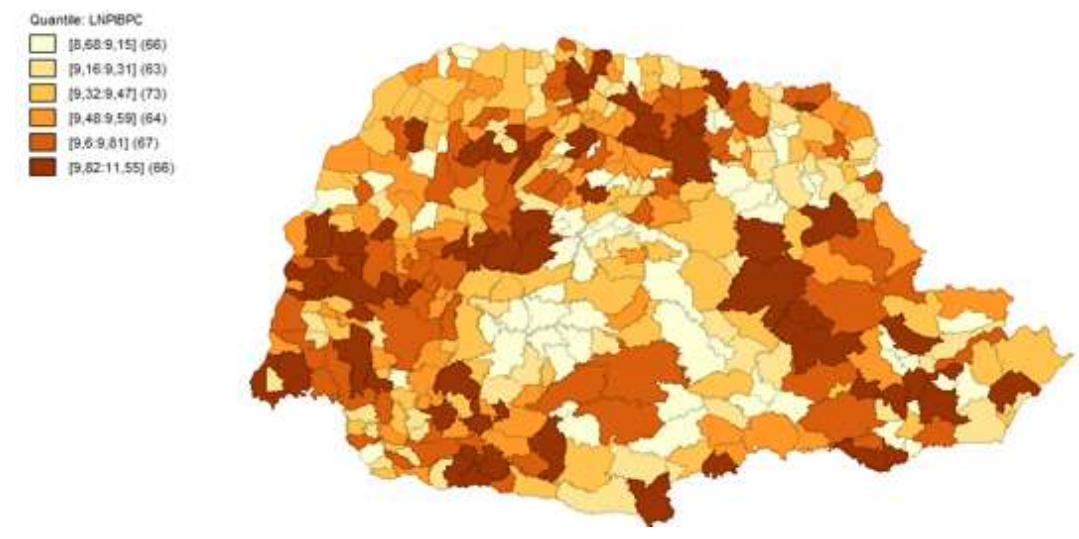

Figura 2: Distribuição geográfica do PIB per capita no Estado do Paraná - 2010 Fonte: Elaboração própria a partir dos dados do IPARDES.

\section{Índice de Moran Global}

Conforme apresentado na metodologia, antes de calcular o Índice de Moran Global propriamente dito, é preciso verificar qual a matriz de pesos espaciais que melhor se adapta aos dados utilizados no trabalho. A Tabela 2 apresenta as diferentes matrizes de pesos calculadas.

Tabela 2: Coeficiente do I de Moran Global para o PIB per capita paranaense

\begin{tabular}{ccc}
\hline Matriz de Pesos & Valor & P-valor \\
\hline Rainha de ordem 1 & 0,1212 & 0,001 \\
Torre de ordem 1 & 0,1486 & 0,001 \\
4 vizinhos mais próximos & 0,1325 & 0,001 \\
5 vizinhos mais próximos & 0,1345 & 0,001 \\
10 vizinhos mais próximos & 0,1327 & 0,001 \\
\hline
\end{tabular}

Fonte: Elaboração própria a partir dos dados do IPARDES.

Todas as matrizes de pesos apresentaram valores positivos $\mathrm{e}$ estatisticamente significantes, indicando a existência de autocorrelação espacial positiva. Como a matriz Torre de ordem 1 foi a que apresentou o maior I de Moran global, esta será a matriz de pesos usada para a estimação do modelo econométrico espacial.

A Figura 3 apresenta o diagrama de dispersão do I de Moran Global para o PIB per capita dos municípios paranaenses. Vê-se claramente no diagrama a presença de autocorrelação positiva, que é reiterado pelo valor do I de Moran Global que excede seu valor esperado, logo pode-se rejeitar a hipótese nula de que não há autocorrelação espacial. 


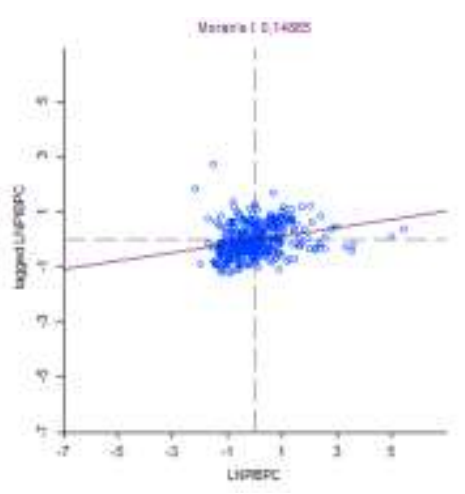

Figura 3: I de Moran Global para o PIB per capita municipal Fonte: Elaboração própria a partir dos dados do IPARDES.

Através da dispersão dos dados apresentada na Figura 3, vê-se que estes estão concentrados predominantemente nos quadrantes 1 e 3, ou seja, municípios com alto PIB per capita tendem a ser circundados por outros municípios com alto valor de seu PIB, enquanto os que detêm PIB per capita baixo também se concentram próximos a municípios com PIB de valor baixo.

A Tabela 3 corrobora essa afirmação ao apresentar o I de Moran Global para as variáveis explicativas do modelo. Todas elas apresentaram um valor significativo, apesar de alguns valores terem sido baixos, mostrando que elas influenciam espacialmente a variável dependente. Já o I de Moran bivariado faz a comparação entre a variável explicada (PIB per capita) e as demais variáveis explicativas, todas também foram estatisticamente significantes e apenas a variável energia diferiu do seu valor esperado ao apresentar um valor negativo.

Tabela 3: Estatística I de Moran Global das variáveis estudadas

\begin{tabular}{c|c|c|c|c}
\hline Variável & $\begin{array}{c}\text { I de Moran } \\
\text { univariado. }\end{array}$ & P-valor & $\begin{array}{c}\text { I de Moran } \\
\text { bivariado }\end{array}$ & P-valor \\
\hline PIB per capita & 0,1486 & 0,001 & & $0,018^{*}$ \\
DespTot & 0,1553 & 0,001 & 0,0571 & $0,009^{*}$ \\
DespPes & 0,1528 & 0,001 & 0,0333 & $0,021^{* *}$ \\
DespAdm & 0,1408 & 0,001 & 0,0196 & $0,013^{*}$ \\
DespSau & 0,1055 & 0,002 & 0,0263 & $0,017^{*}$ \\
DespEduc & 0,0902 & 0,007 & 0,0216 & $0,029^{* *}$ \\
Distância & 0,6848 & 0,001 & 0,0050 & $0,001^{*}$ \\
Densidade & 0,4496 & 0,001 & 0,1008 & $0,059^{* * *}$ \\
Energia & 0,0315 & 0,017 & $-0,0351$ & \\
\hline
\end{tabular}

${ }^{1}$ Entre a variável dependente PIB per capita e as variáveis explicativas. O p-valor foi baseado em 999 permutações aleatórias.

Nota: Coeficientes estaticamente significante a $1 \%^{*}, 5 \%{ }^{* *}$ e a $10 \%{ }^{* * *}$.

Fonte: Elaboração própria a partir dos dados do IPARDES.

Através dos resultados obtidos com o I de Moran, tanto o univariado quanto o bivariado, pode-se afirmar que o PIB per capita dos municípios paranaenses sofre 
influência espacial das demais variáveis explicativas do modelo, logo, é pertinente o uso de econometria espacial para realizar a análise desse modelo.

\section{Índice de Moran Local}

Uma vez que os valores do índice de Moran Global foram significativos e apontaram a necessidade do uso de econometria espacial, pode-se partir para uma análise do I de Moral Local, que apresenta os clusters do PIB per capita municipal através de padrões de correlação Alto-Alto (AA), Baixo-Baixo (BB), Alto-Baixo (AB) e Baixo-Alto (BA). A Figura 4 apresenta o mapa de clusters do PIB per capita municipal em 2010. É possível verificar três regiões com dependência espacial estatisticamente significantes. A região central do estado apresenta 0 comportamento do tipo baixo-baixo (Q3). Por sua vez, as regiões Metropolitana de Curitiba, e as regiões Oeste e Sudoeste e algumas cidades do Norte Central, como Arapongas e Cianorte apresentam um padrão do tipo alto-alto (Q1), ou seja, os municípios apresentam altos valores do seu PIB per capita e estão circundados por outros municípios que apresentam esse valor também alto.
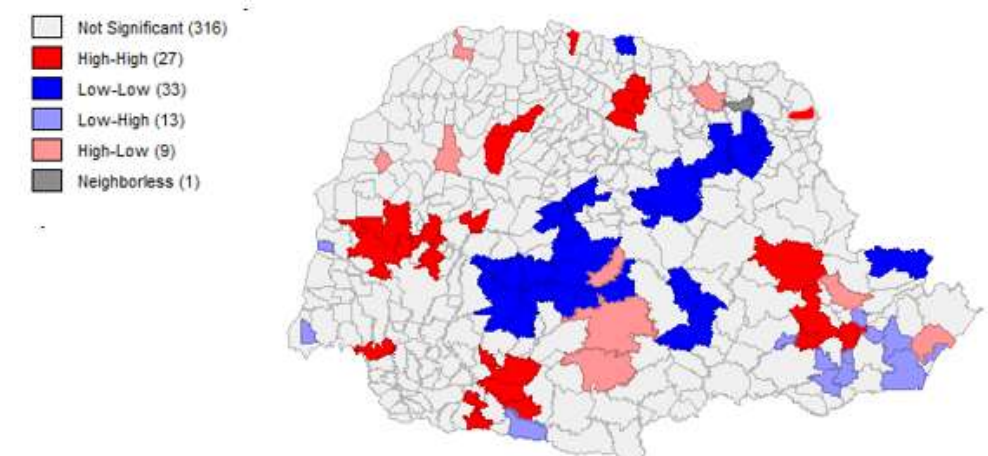

Figura 4: Mapa de clusters do PIB per capita paranaense em 2010 Fonte: Elaboração própria a partir dos dados do IPARDES.

Para uma melhor verificação do impacto espacial das variáveis explicativas sobre o PIB per capita municipal, a Figura 5 apresenta o resultado do I de Moran Local bivariado, estando o PIB per capita no eixo $X$ e cada uma das variáveis explicativas no eixo $\mathrm{Y}$.

Nos mapas de despesas, vê-se uma tendência nas regiões Central e Norte Pioneiro de apresentarem clusters do tipo baixo-baixo, ou seja, baixo PIB per capita combinado com despesas baixas, enquanto a região de fronteira do estado, que contempla cidades como Foz do Iguaçu e Marechal Cândido Rondon apresentaram 
clusters do tipo alto-alto, ou seja, um valor alto do seu PIB per capita combinado com gastos com despesas altos.

Quanto ao mapa de densidade demográfica, veem-se claramente dois clusters de valor alto-alto, ou seja, PIB per capita alto combinado com grande povoamento, na região metropolitana de Curitiba e no Norte Central, que engloba as cidades de Londrina e Maringá. Enquanto há um grande cluster do tipo baixo-baixo na região central do estado, que é, conhecidamente, a região mais pobre e mais rural do Paraná.
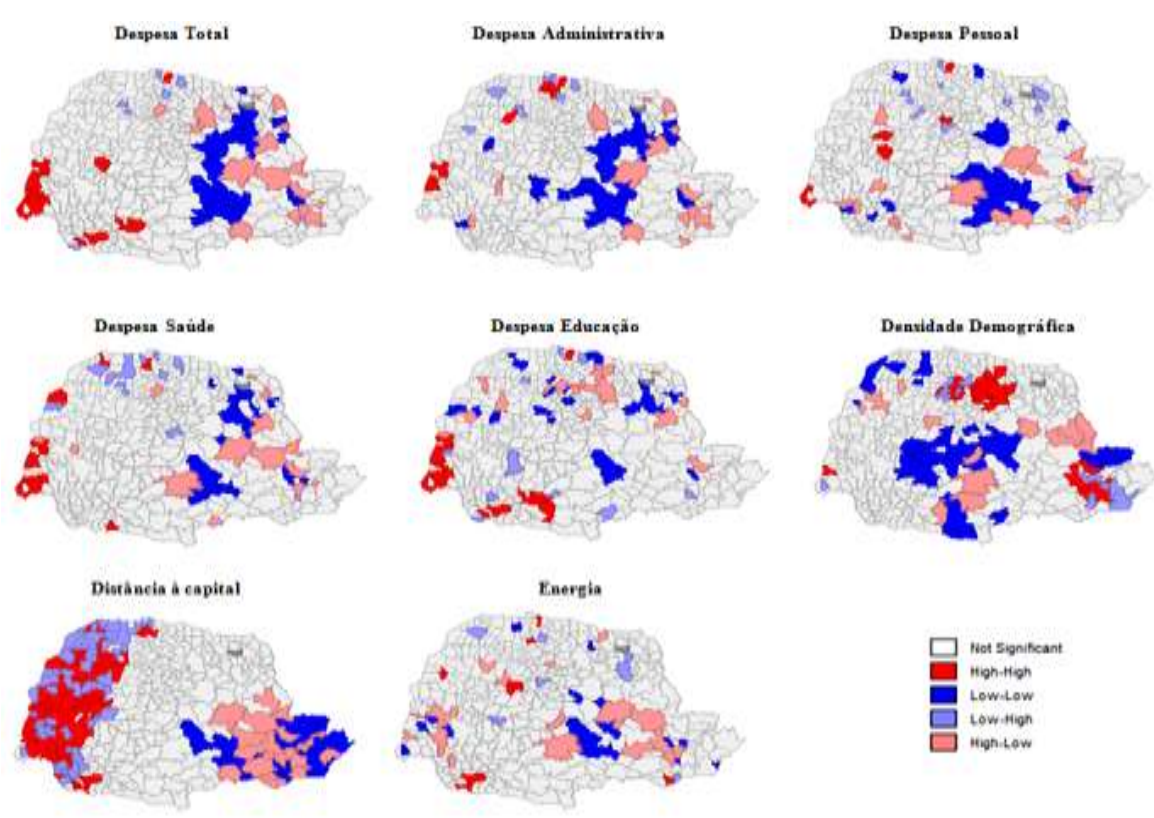

Figura 5: Clusters bivariados entre o PIB per capita e as variáveis explicativas Fonte: Elaboração própria a partir dos dados do IPARDES.

O mapa de clusters da distância à Capital mostra as regiões que circundam a região metropolitana de Curitiba com padrão alto-baixo, ou seja, PIB per capita alto combinado com pequena distância à Capital, enquanto que as regiões mais distantes apresentam um padrão alto-alto e baixo-alto.

Quanto à variável Energia, veem-se alguns clusters alto-baixo nas regiões Central, Oeste e Metropolitana do Estado, ou seja, alto PIB per capita combinado com baixo consumo de energia, sempre próximas de clusters com padrão baixobaixo (baixo PIB per capita e baixo consumo de energia).

\section{Resultados do Modelo econométrico}

A Tabela 4 apresenta os resultados do modelo proposto estimado por Mínimos Quadrados Ordinários. Os resultados mostram que há um impacto 
significativo das variáveis despesa total, despesa com pessoal e despesa administrativa sobre o PIB per capita municipal, o que era esperado, uma vez que o aumento das despesas é um sinal de que o município está investindo em seu crescimento. Já as variáveis despesa com educação e despesa com saúde apresentaram sinal contrário ao esperado pela teoria, mostrando que o aumento dessas despesas leva a um decréscimo do PIB per capita, uma explicação poderia ser de que um gasto elevado com educação afeta negativamente o PIB do período, pois esse é um investimento de longo prazo que tende a mostrar seus resultados apenas no futuro.

No que se refere às despesas com saúde, os resultados sugerem que os municípios tendem a gastar com ações de promoção da saúde, que também apresentam resultados de longo prazo, e gastar com a rede municipal de saúde, que inclui hospitais e postos de saúde municipais, assim, maior gasto com esses estabelecimentos sugere que a população tem baixa qualidade de vida, logo o PIB per capita pode ser influenciado negativamente. As variáveis distância à capital e energia elétrica apresentaram valores positivos e significativos, já a variável densidade demográfica teve seu valor negativo, mostrando que um aumento da densidade demográfica leva a uma queda do PIB per capita.

Tabela 4: Resultado da Regressão por MQO

\begin{tabular}{c|c}
\hline Variável & MQO \\
\hline Constante & $0,7240^{\star *}$ \\
InDespTot & $0,4344^{*}$ \\
InDespPes & $0,4101^{*}$ \\
InDespAdm & $0,1284^{*}$ \\
InDespSau & $-0,0555^{\star *}$ \\
InDespEduc & $-0,0791^{* *}$ \\
InDistância & $0,0422^{*}$ \\
InDensidade & $-0,0118^{\star *}$ \\
InEnergia & $0,0136^{*}$ \\
\hline $\mathrm{R}^{2}$ & 0,76
\end{tabular}

Nota: Coeficientes estaticamente significante a $1 \%{ }^{*}$ e a $10 \%$ **.

Fonte: Elaboração própria a partir dos dados do IPARDES.

Para o modelo de MQO, o teste $R^{2}$ indicou que as variáveis explanatórias explicam cerca de $76 \%$ do PIB per capita dos municípios paranaenses. O teste "Condition Number" apresentou valor inferior a 30, indicando a não existência de multicolinearidade. Por fim, ao analisar o teste Breush-Pagan que tem como hipótese nula a homocedasticidade, é possível rejeitar com $1 \%$ de significância a hipótese nula, ou seja, o modelo apresenta o problema da heterocedasticidade, fato bastante corriqueiro nos estudos de econometria espacial. 


\section{Modelos econométricos espaciais}

Após a estimação do modelo por $\mathrm{MQO}$, deve-se testar a presença de autocorrelação através das estatística ML $\rho$ e ML入. Caso os dois testes não sejam significantes, o modelo não apresenta autocorrelação espacial e, dessa forma, o modelo "tradicional" já calculado é o mais apropriado, porém, se os dois testes sejam significantes, calcula-se as versões robustas desses testes, $M L^{*} \rho$ e $M L^{*} \lambda$ e estima-se o modelo que for mais significante. A Tabela 5 apresenta o diagnóstico de dependência espacial a partir do resultado estimado por MQO.

Tabela 5: Diagnóstico de Dependência Espacial

\begin{tabular}{c|c|c}
\hline Teste & Valor & Prob. \\
\hline $\mathrm{ML} \lambda$ (erro) & 5,0724 & 0,0243 \\
$\mathrm{ML}^{*} \lambda$ (erro robusto) & 3,2640 & 0,0708 \\
$\mathrm{ML} \rho$ (defasagem) & 2,4243 & 0,1194 \\
$\mathrm{ML}^{*} \rho$ (defasagem robusta) & 0,6159 & 0,4325 \\
\hline
\end{tabular}

Fonte: Elaboração própria a partir dos dados do IPARDES.

Como 0 teste do Multiplicador de Lagrange do erro mostrou-se estatisticamente significante, enquanto o teste do Multiplicador de Lagrange da defasagem não foi significativo nem a $10 \%$, verifica-se que o modelo de erro espacial é a regressão mais indicada a ser feita. O modelo passa a ser:

\section{PIBpc $=\alpha+\beta_{1}$ DespTot $+\beta_{2}$ DespPes $+\beta_{3}$ DespAdm $+\beta_{4}$ DespSaúde $+\beta_{5}$ DespEduc + $\beta_{6} D D+\beta_{7}$ Dist $+\beta_{8}$ Energia $+\mu$}

\section{Em que $\mu=\lambda W \mu+\varepsilon$}

Assim, a Tabela 6 apresenta os resultados do modelo por Erro Espacial e por Durbin Espacial. Na regressão com Erro Espacial, vê-se que os coeficientes mantêm seus sinais, bem como são todos significativos, porém, todos têm seus valores um pouco diminuídos em função da adição do componente de erro $(\lambda)$, o qual apresentou sinal positivo e significante, indicando que a defasagem espacial encontra-se no erro do modelo.

Portanto, a regressão com modelo de erro espacial mostra que, quando a despesa total do município aumenta 1\%, o PIB per capita municipal aumenta em $0,45 \%$. Essa despesa se mostra como a mais significativa dentre todas as variáveis do modelo, indicando que os municípios paranaenses devem aumentar suas despesas totais, as quais englobam as despesas correntes e de capital, pois 
estas são as principais responsáveis por aumentar o PIB municipal, mostrando que, na medida em que os municípios aumentam seus gastos com infraestrutura, eles estão contribuindo para seu próprio crescimento. Segundo Forlin e Rodrigues (2012), este tipo de gasto certamente afeta a qualidade de vida e a produtividade dos indivíduos, gerando externalidades que impactam positivamente o crescimento econômico dos municípios. As variáveis energia elétrica e distância à capital, apesar de mostrarem retornos positivos, têm pouco impacto sobre o PIB municipal.

O valor do $\mathrm{R}^{2}$ aumentou consideravelmente na regressão com Erro Espacial, mostrando que, no novo modelo, $81 \%$ das variações do PIB per capita municipal são explicadas por variações nas variáveis explicativas. Porém, o teste de Breush-Pagan mostra que os erros continuam heterocedásticos.

Tabela 6: Resultado da Regressão através dos modelos de Econometria Espacial

\begin{tabular}{ccc}
\hline Variável & Erro Espacial & Durbin Espacial \\
\hline Constante & $0,8675^{\star * *}$ & $3,0999^{*}$ \\
InDespTot & $0,4456^{*}$ & $0,7672^{*}$ \\
InDespPes & $0,4063^{*}$ & $0,4201^{*}$ \\
InDespAdm & $0,1399^{\star}$ & $-0,1591^{*}$ \\
InDespSau & $-0,0529^{\star * *}$ & $0,2059^{*}$ \\
InDespEduc & $-0,0757^{\star * *}$ & $0,2191^{*}$ \\
InDistância & $0,0354^{* *}$ & \\
InDensidade & $-0,0249^{\star * *}$ & \\
InEnergia & $0,0143^{* *}$ & \\
W_PIB & & $0,9343^{*}$ \\
W_DespTot & & $0,7608^{*}$ \\
W_DespPes & & $-0,7751^{*}$ \\
W_DespAdm & & $0,1738^{*}$ \\
W_DespSau & & $0,3161^{*}$ \\
W_DespEduc & & $0,0628^{* * *}$ \\
$\wedge$ & $0,1738^{*}$ & \\
\hline$R^{2}$ & 0,81 & 0,89
\end{tabular}

Nota: Coeficientes estaticamente significante a $1 \%^{*}, 5 \%{ }^{* *}$ e a $10 \%{ }^{* * *}$. Fonte: Elaboração própria a partir dos dados do IPARDES.

Por fim, a segunda coluna da Tabela 6 apresenta os resultados do modelo Durbin Espacial, em que é incorporado o efeito transbordamento das variáveis explicativas da vizinhança assim como a defasagem da variável dependente. Esse modelo mostrou-se como o mais completo e que melhor explicou o PIB per capita municipal. Foram retiradas as variáveis que não eram de gasto público com o objetivo de analisar o retorno bruto dos gastos sobre o PIB per capita municipal. Vêse que os resultados das variáveis despesa total e despesa com pessoal 
melhoraram, enquanto que a variável despesa administrativa inverteu seu sinal, passando a contribuir negativamente com o PIB, enquanto as variáveis de despesa com saúde e educação passaram a ser positivas.

Quanto às variáveis com defasagem espacial (possuem um $W$ na frente do nome), todas continuaram significativas, porém com inversão do sinal da variável despesa com pessoal, que passa a afetar negativamente o PIB per capita municipal e da variável despesa administrativa, que volta a ser positiva. A defasagem espacial da variável dependente PIB per capita mostrou-se positiva e altamente significante, indicando que o crescimento de uma cidade impacta fortemente no crescimento das cidades que estão próximas.

Assim, a partir dos resultados apresentados pelos três modelos propostos, chega-se à conclusão de que os gastos públicos são fatores determinantes para o crescimento das cidades bem como para o desenvolvimento das regiões, bem como são importantes ao possuírem o efeito de espraiamento, ou seja, eles detêm o efeito de impulsionar o crescimento não só da própria cidade onde os gastos estão ocorrendo, mas também estimular o crescimento das cidades próximas, bem como da região como um todo.

\section{Considerações finais}

O presente trabalho objetivou investigar a relação existente entre o crescimento econômico, considerando o Produto Interno Bruto (PIB) per capita e as variáveis que compõem os gastos públicos (gasto total, gastos com pessoal, gastos administrativos, gastos com saúde e com educação) dos 399 municípios paranaenses no ano de 2010. Para tal, o artigo apresentou um modelo de econometria espacial, que difere dos métodos tradicionais ao acrescentar uma matriz de pesos espaciais no modelo, objetivando verificar se existe autocorrelação espacial entre as variáveis de estudo.

Após os testes confirmarem a existência de correlação espacial entre o PIB per capita municipal e as variáveis explicativas, foram estimados três modelos econométricos: o de mínimos quadrados ordinários, que não inclui a matriz de pesos, o modelo de erro espacial e o modelo de Durbin espacial, onde os dois consideram a matriz de pesos espaciais no cálculo.

Os resultados das regressões mostraram que há um impacto significativo das variáveis despesa total, despesa com pessoal e despesa administrativa sobre o PIB per capita municipal, o que era esperado, uma vez que o aumento das despesas é 
um sinal de que o município está investindo em seu crescimento. Já as variáveis despesa com educação e despesa com saúde apresentaram sinal contrário ao esperado pela teoria, mostrando que o aumento dessas despesas leva a um decréscimo do PIB per capita. Porém, o resultado mais significativo foi o da despesa total, indicando que os municípios paranaenses devem aumentar suas despesas totais, as quais englobam as despesas correntes e de capital, pois estas são as principais responsáveis por aumentar o PIB municipal, revelando que, na medida em que os municípios aumentam seus gastos com infraestrutura, eles estão contribuindo para seu próprio crescimento bem como para o crescimento das cidades próximas.

Assim, a partir dos resultados apresentados pelos três modelos propostos, chega-se à conclusão de que os gastos públicos são fatores determinantes para o crescimento das cidades bem como para o desenvolvimento das regiões, bem como são importantes ao possuírem o efeito de espraiamento, ou seja, eles detêm o efeito de impulsionar o crescimento não só da própria cidade onde os gastos estão ocorrendo, mas também estimular o crescimento das cidades próximas, bem como da região como um todo.

Sendo assim, conclui-se que os governos municipais devem procurar promover o crescimento do PIB alocando seus gastos em áreas que busquem garantir uma melhor estrutura de investimentos para que dessa forma sejam capazes de atrair novos empreendimentos e, consequentemente, reduzir as disparidades ora observadas, bem como deve haver uma coordenação entre municípios vizinhos de forma que o crescimento de uma cidade promova o crescimento das cidades das redondezas, o que significa um ganho para a região como um todo.

Como ponto de esclarecimento, deve-se ressaltar, conforme destacam Bogoni, Hein e Beuren (2011), que o presente estudo não contemplou os efeitos da tributação no crescimento econômico (PIB) dessas cidades. No estudo não se assumiu que os gastos com tributos e os gastos públicos não são independentes (para gastar mais, o governo deve arrecadar mais). Tal observação pode ser o passo seguinte em próximas pesquisas que avaliem a participação do governo no crescimento econômico, principalmente contemplando a participação dos tributos e transferências. 


\section{REFERÊNCIAS}

ALMEIDA, E. S. Econometria espacial aplicada. Campinas: Editora Alínea, 2012.

ANSELIN, L. Local indicators of spatial association - LISA, Geographical Analysis, vol. 27 (2), pp. 93-115, 1995.

ANSELIN, L. Spatial Econometrics. USA: University of Texas, 1999.

ARRAES, R. A.; TELES, V. K. Política fiscal e crescimento econômico: aspectos teóricos e evidências empíricas para as regiões brasileiras. In: Revista Econômica do Nordeste, Fortaleza, v. 32, n. Especial, p. 676-690, nov. 2001.

BARRO, R.J. Government spending in a simple model of endogenous growth. In: Journal of Political Economy, v. 98, p. 103-125, Oct. 1990.

BARROS, N. A. L. R.; FERREIRA, M. O. Evidências empíricas sobre a relação entre formação do PIB e gastos públicos nos municípios pernambucanos no período de 1997 a 2012. In: Anais do XVI Encontro de Economia da Região Nordeste - Anpec Nordeste, Recife, Pernambuco, 2012.

BOGONI, N. M.; HEIN, N.; BEUREN, I. M. Análise da relação entre crescimento econômico e gastos públicos nas maiores cidades da região Sul do Brasil. In: Revista de

Administração Pública, Rio de Janeiro, n.45, p.159-179, jan./fev. 2011.

CASSUSSE, F. C. C., et al. Uma análise espacial do nível de desenvolvimento associado a capital humano e a capital fixo no estado de Minas Gerais. In: Revista Paranaense de Desenvolvimento, Curitiba, n.112, p.159-179, jan./jun. 2007.

COLUSSO, M. V. S. Degradação ambiental versus crescimento econômico: a curva de Kuznets ambiental para o cerrado. Maringá, 2012, 113p. Dissertação (Mestrado em Economia) - Universidade Estadual de Maringá.

DINIZ, C. C.; CROCCO, M. Bases teóricas e instrumentais da economia regional e urbana e sua aplicabilidade ao Brasil: uma breve reflexão. In: DINIZ, C. C.; CROCCO, M. (Orgs). Economia regional e urbana: contribuições teóricas recentes. Belo Horizonte: Editora UFMG, 2006.

FIGUEIREDO, A. M. R. Resposta da produção agrícola aos preços na região CentroOeste: uma análise de econometria espacial para o período 1975/1995-1996. Viçosa, 2002, 184p. Tese (Doutorado em Economia) - Universidade Federal de Viçosa.

FORLIN, J. A.; RODRIGUES, R. V. Finanças públicas e crescimento econômico nos municípios paulistas. In: Revista Economia e Desenvolvimento, n. 24, vol. 2, 2012.

FURTADO, C. O mito do desenvolvimento econômico. Rio de Janeiro: Paz e Terra, 1974.

GUIMARÃES NETO, L. Desigualdades e políticas regionais no Brasil: caminhos e descaminhos. In: Planejamento e Políticas Públicas, IPEA, n. 15, jun. 1997.

IPARDES - Instituto Paranaense de Desenvolvimento Econômico e Social. Bases de dados. Disponível em : <http://www.ipardes.gov.br/imp/index.php>. Vários acessos, 2013.

LIMA, A. C. C.; LIMA, J. P. R. Mecanismos recentes de desenvolvimento regional no Brasil. In: Revista da Sociedade Brasileira de Economia Política. São Paulo, n. 28, p. 71-104, fev 2011. 
MARQUES JUNIOR, L. S. et al. O papel da política fiscal local no crescimento econômico de cidades: uma evidência empírica para o Brasil. In: Anais do XXXIV Encontro Nacional de Economia, Salvador: Anpec, 2006.

OLIVEIRA, C. A. Política fiscal local e o crescimento econômico dos municípios gaúchos (1996 - 2001). In: Anais do III Encontro de Economia Gaúcho. Porto Alegre, 2006.

ROCHA, F.; GIUBERT, A. C. Composição dos gastos públicos e crescimento econômico: um estudo em painel para os estados brasileiros. In: Anais do XXXIII Encontro Nacional de Economia, Natal: ANPEC, 2005.

RODRIGUES, R. V.; TEIXEIRA, E. C. Gasto público e crescimento econômico no Brasil: uma análise comparativa dos gastos das esferas de governo. In: Revista Brasileira de Economia. Rio de Janeiro, v. 64, n. 4, p. 423-438, out./dez. 2010.

SILVA, L. N. S. da; BORGES, M. J.; PARRÉ, J. L. Distribuição Espacial da Pobreza no Paraná. In: Anais do XVI Encontro de Economia da Região Sul - Anpec Sul, Curitiba, Paraná, 2013.

\section{NOTAS DE AUTOR}

\section{CONTRIBUIÇÃO DE AUTORIA}

Michele Aparecida Nepomuceno Pinto - Concepção. Coleta de dados, Análise de dados, Elaboração do manuscrito, revisão e aprovação da versão final do trabalho

José Luiz Parré- Concepção e elaboração do manuscrito. Participação ativa da discussão dos resultados; Revisão e aprovação da versão final do trabalho.

\section{FINANCIAMENTO}

Não se aplica.

CONSENTIMENTO DE USO DE IMAGEM

Não se aplica.

APROVAÇÃO DE COMITÊ DE ÉTICA EM PESQUISA

Não se aplica.

\section{CONFLITO DE INTERESSES}

Não se aplica.

\section{LICENÇA DE USO}

Este artigo está licenciado sob a Licença Creative Commons CC-BY. Com essa licença você pode compartilhar, adaptar, criar para qualquer fim, desde que atribua a autoria da obra.

\section{HISTÓRICO}

Recebido em: 23-08-2018

Aprovado em: 05-11-2018 